\title{
Sedimentbeschaffenheit und Bakteriengehalt im Sediment eines zukünftigen Verklappungsgebietes von Industrieabwässern nordwestlich Helgolands
}

\author{
W. HrCKEL \\ Biologische Anstalt Helgoland, Meeresstation, Helgoland
}

\begin{abstract}
Sediment properties and bacterial numbers in the sediment of a sea area selected for industrial waste disposal north west of Helgoland. The disposal of industrial wastes containing sulphuric acid and ferrous sulphate from a titanium oxide factory is scheduled to start early in 1969 within an area of $2.5 \times 5$ miles at a distance of 11.5 miles north west from Helgoland (German Bight, North Sea). At 7 stations of this area sediment investigations were made on cores taken with a Reineck box sampler. In September 1967 and March 1968 grain size, ignition loss, water content, redox potential, and numbers of heterotrophic bacteria in the sediment were analyzed. In parallel estimations of bacterial numbers a mean deviation from the mean value was found at the surface of one core $\left(600 \mathrm{~cm}^{2}\right)$ of $11 \%$, at one Decca-position of $16 \%$, and in the whole area investigated of $43 \%$. Bacterial numbers amounted to 2.5 to $12.3 \times 10^{6} \mathrm{per} \mathrm{ml}$ in September 1967 , and 0.08 to $0.98 \times 10^{6}$ in March 1968 in the upper two millimeters of the sediment. Ignition loss was less than $1 \%(0.2$ to $0.8 \%$. The sediment consisted of well sorted fine or medium sand. A small area of coarse sand with gravel probably showed the local influence of irregular bottom currents. A clay layer in $15 \mathrm{~cm}$ substrate depth indicated variations in sedimentation history. In September 1967, the new sand layer - found after the heavy gales in winter 1966/67 - was repopulated by macrofauna. The previous sediment surface was detected in about $10 \mathrm{~cm}$ substrate depth; it yielded a higher bacterial count. In September 1967, bacterial numbers at the sediment surface were 10 to 100 times higher than in March 1968, the organic content of the sediment remaining about the same. Correlations between bacterial numbers and increasing content of organic matter revealed a very slow increase of bacteria in spring, a rapid one in autumn. The planned disposal of industrial wastes will presumably not affect the benthos via poisonous actions, however sedimentation of the ferrous hydroxide could be dangerous. To study the formation and sedimentation of hydroxide particles, an experiment was carried out in the moving and aerated water of a "planktonkreisel", a device for rearing plankton. The size of the hydroxide particles increases within a few days and grows bigger in turbulent than in nonturbulent water. In this experiment, a hydroxide layer led to a consolidation of the sand surface after one month $\left(20^{\circ} \mathrm{C}\right)$. The biological consequences of such a consolidated layer for the mikro-, meio- and makrobenthos awaits further investigations.
\end{abstract}

\section{EINLEITUNG}

Im Jahr 1969 soll in einem 2,5 $\times 5$ Seemeilen großen Gebiet 11,5 sm nordwestlich Helgolands mit dem Einbringen großer Mengen (1200 Tonnen pro Tag) von Abfall- 


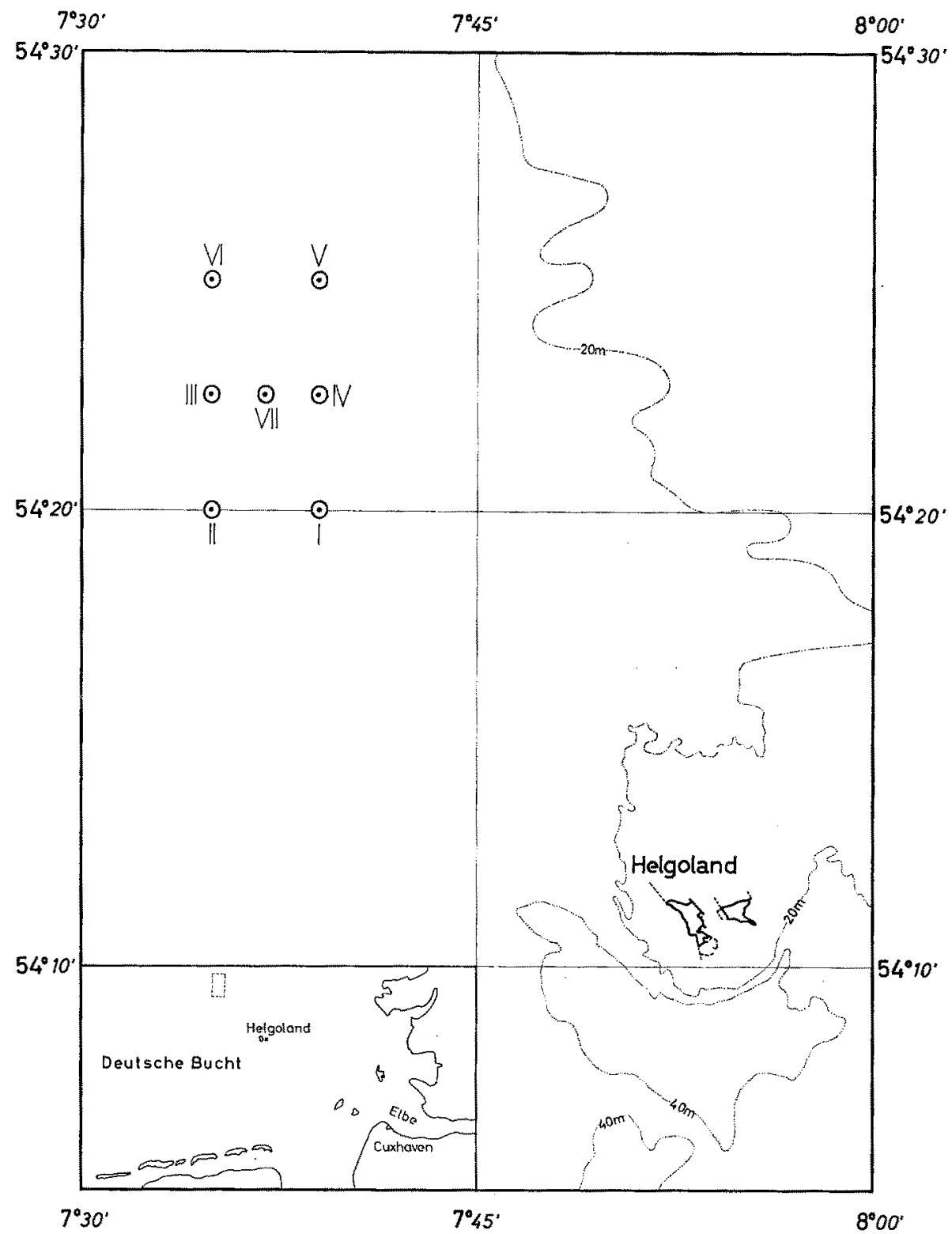

Abb. 1: Lage des zukünttigen Verklappungsgebiets mit den 7 untersuchten Stationen

stoffen einer Titandioxid-Fabrik begonnen werden. Diese zur Verklappung vorgesehenen Stoffe bestehen hauptsächlich aus Eisensulfat und Schwefelsäure. Bereits jetzt gilt die Aufmerksamkeit der Biologischen Anstalt Helgoland dem zuküntigen Verklappungsgebiet; es sollen die natürlichen Verhältnisse des Okosystems im Wasser und besonders am Meeresboden vor dem Beginn der Verklappung beurteilt werden, um mög- 
liche Änderungen und Schädigungen der OKkosysteme durch die Industrieabwässer erkennen zu können.

Das hier untersuchte zukünftige Verklappungsgebiet, dessen Lage aus Abbildung 1 hervorgeht, ist von Helgoland aus mit kleineren Schiffen rasch zu erreichen. Die Wassertiefe beträgt 23,5 bis $27,5 \mathrm{~m}$. Das Bodenrelief, das für unsere Untersuchungen besonders wichtig ist, wird in Abbildung $2 \mathrm{a}$ und $\mathrm{b}$ durch die Reproduktion des Echogramms vom zukünftigen Verklappungsgebiet und dessen Umgebung (aufgenommen im Herbst 1968) dargestellt. Der bei der Aufnahme des Echogramms gefahrene Kurs ist in Abbildung $3 \mathrm{zu}$ ersehen. Der Boden ist nur leicht gewellt, größere Tiefendifferenzen als $4 \mathrm{~m}$ werden nicht gefunden. Anders ist dies $4 \mathrm{sm}$ westlich des Gebietes, wo das Echogramm einen raschen Abfall des Bodens auf über $40 \mathrm{~m}$ anzeigt. Es ist dies der östliche Rand einer etwa $40 \mathrm{~m}$ tiefen Mulde, die sich westlich des Verklappungsgebiets über eine Entfernung von $20 \mathrm{sm}$ hinzieht und deren Sediment sich wesentlich von dem des Verklappungsgebiets unterscheidet (Hickel \& GunkeL 1968).

Das Untersuchungsgebiet liegt fern genug von den Hauptquellen der Verunreinigung der Deutschen Bucht, den Mündungen von Elbe und Weser, und abseits vom Einfluß der Wattengebiete sowie der Konvergenzzone der Deutschen Bucht, die sich in Süd-Nord-Richtung östlich von Helgoland erstreckt. Unser Gebiet kann für weite Teile der Deutschen Bucht mit weniger als $30 \mathrm{~m}$ Wassertiefe als repräsentativ angesehen werden.

Die Hydrographie der südlichen Deutschen Bucht läßt sich aus den Arbeiten von Neumann \& Meier (1964), Goedecke (1939, 1941, 1968) und Kalle (1956) ersehen. Besonders wichtig für unsere Betrachtungen ist die Stärke des Tidenstroms, die zwischen 40 bis maximal $70 \mathrm{~cm} / \mathrm{sec}$ liegt. Eine Wasserverschiebung durch die Tide von $9 \mathrm{~km}$ und ein Reststrom von 5 bis $10 \mathrm{~cm} / \mathrm{sec}$ wurden beobachtet. Goedecke (1941) gibt für die Deutsche Bucht 5 zyklonale Wirbel des Reststroms an, die aber nicht immer an denselben Stellen angetroffen werden. Einer dieser Wirbel liegt im Bereich des zukünftigen Verklappungsgebiets.

Das Sediment des Untersuchungsgebiets besteht aus feinsandigem Mittelsand oder mittelsandigem Feinsand, wovon aber Ausnahmen gefunden werden. Eine reiche Tierbesiedlung des gut durchlüfteten Sediments ist die Regel.

Die hier vorgelegten Untersuchungen am Sediment des zukünftigen Verklappungsgebiets im Herbst 1967 und Frühjahr 1968 sind ein erster Beitrag zur Feststellung der natürlichen Verhältnisse in den obersten etwa $20 \mathrm{~cm}$ des Bodens vor dem Einbringen der Industrieabwässer. Die intensive Bearbeitung dieses kleinen Sedimentareals bot ferner die Grundlage zur Beurteilung der natürlichen Heterogenität der gemessenen Größen, nämlich Korngrößenverteilung, Gehalt an organischer Substanz, Wassergehalt und Keimzahl der Bakterien in der Deutschen Bucht.

\section{MATERIAL UND METHODEN}

Während einer zehntägigen Fahrt des VFS „Gauss“ im September 1967 wurden auf 7 Stationen, während zwei Ausfahrten mit FK „Uthörn“ im März 1968 auf den gleichen Stationen insgesamt etwa 35 Sedimentkerne mit dem Kastengreifer nach 


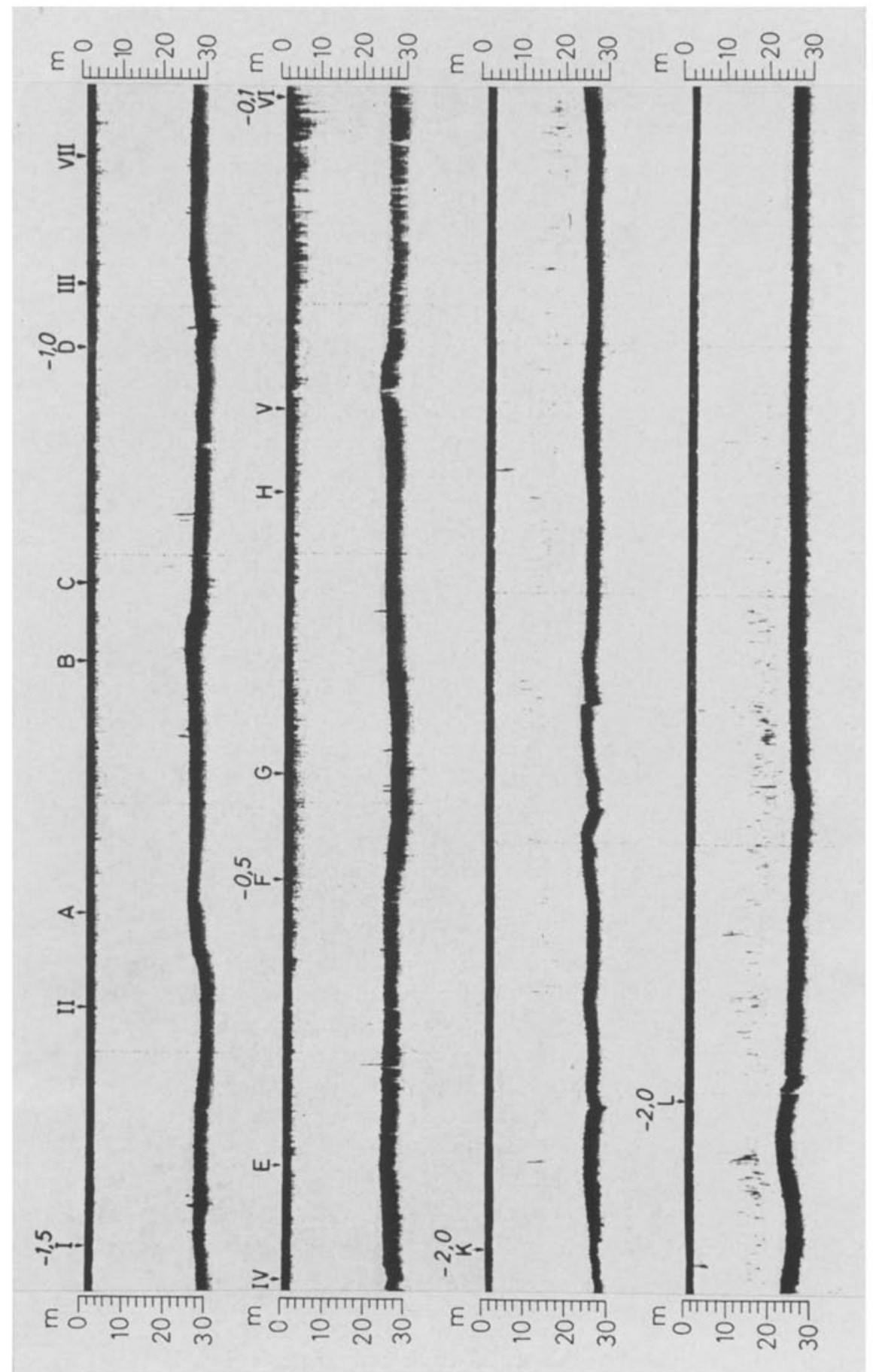




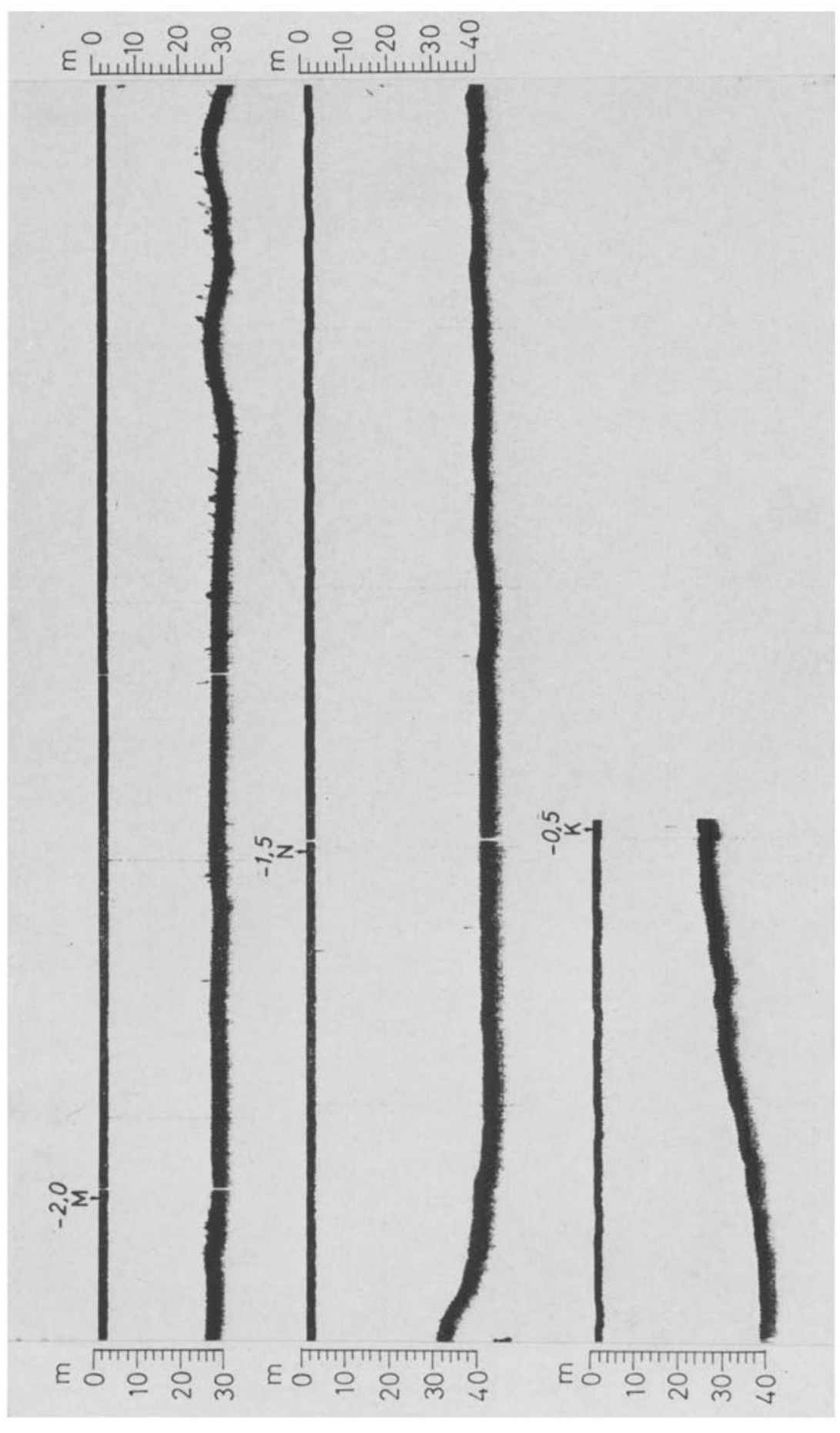

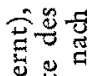

巳

政

․․․

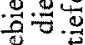

0 몬

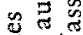

0

on

50

\%

5

o

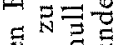

的寻

的到

ह

:

运要

हा ते

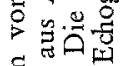

点点离范

$\checkmark$ 舟

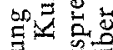

o $5:$

品

专要

용

.

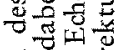

도으.

ats

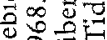

$600:=1$

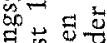

궁

讨㐘

玒

密

$>+v^{2}$

뭉을

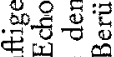

다

:

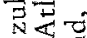

घ $द$ क

$\Rightarrow$ 豆

है)

.

路

$50:$

दे छ

$\ddot{4}$

त

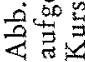




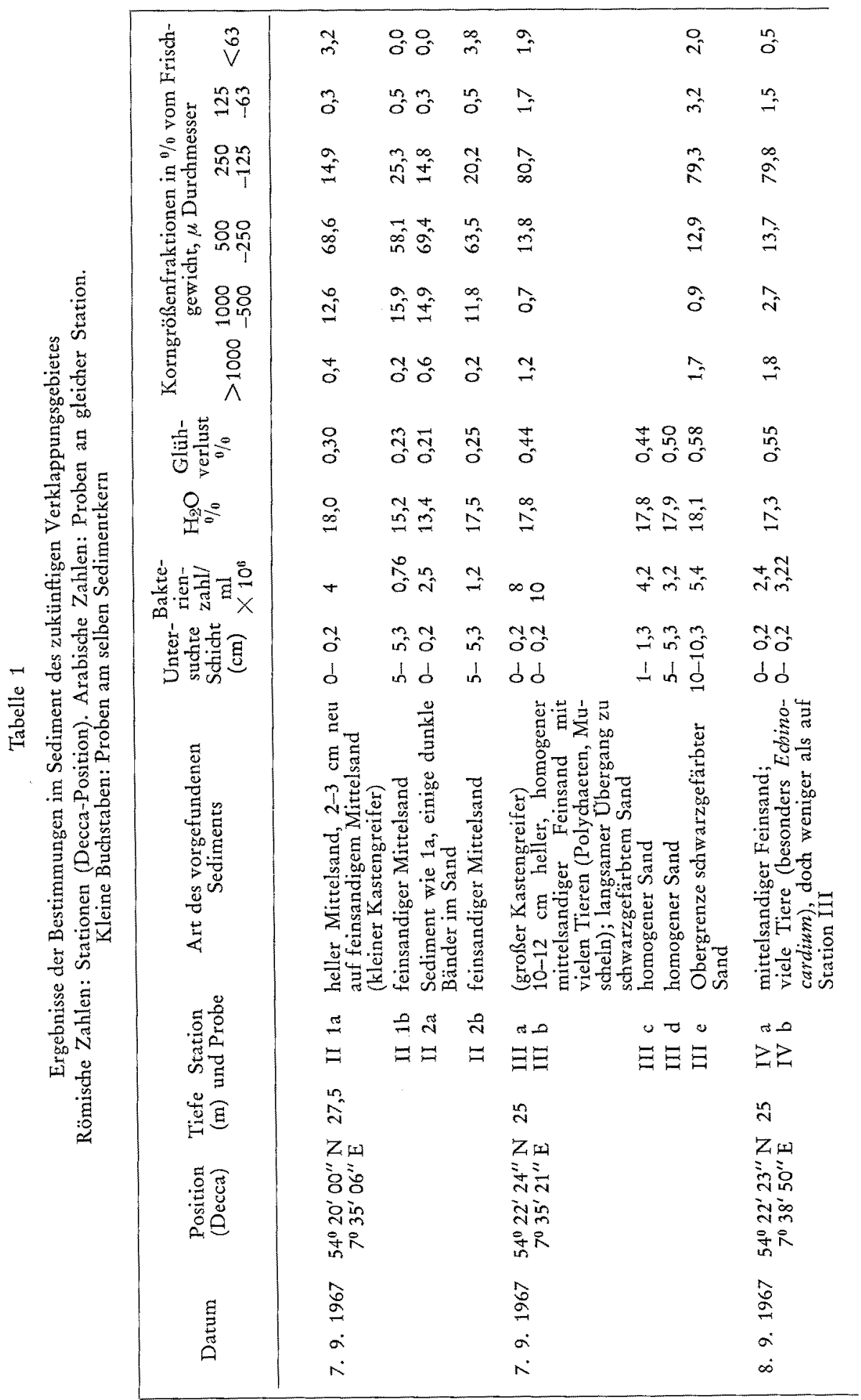




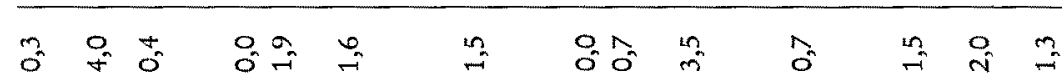

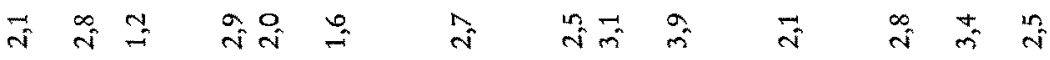

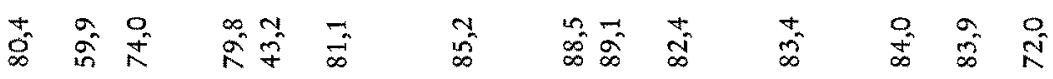

$=$ 苛

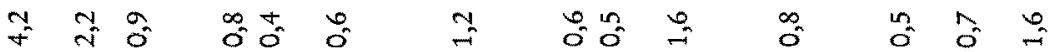

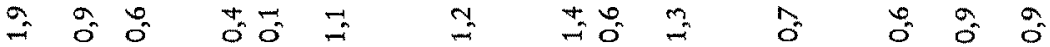

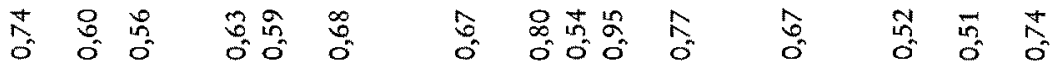

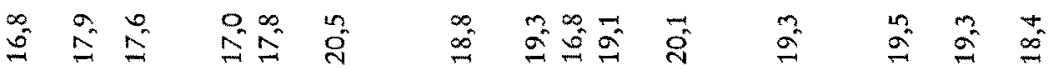

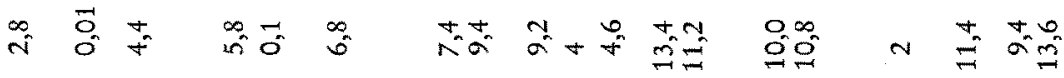

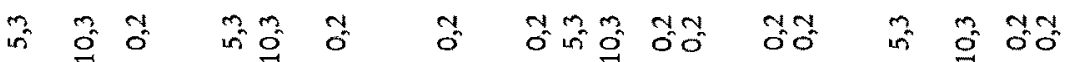

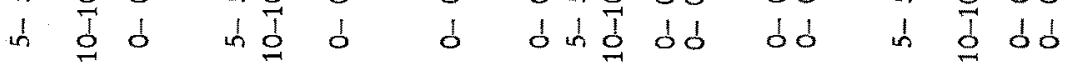

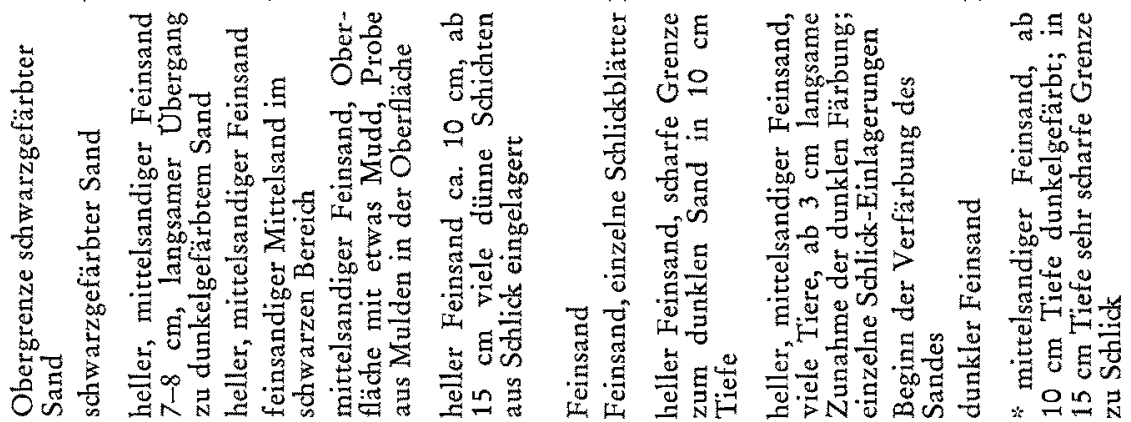

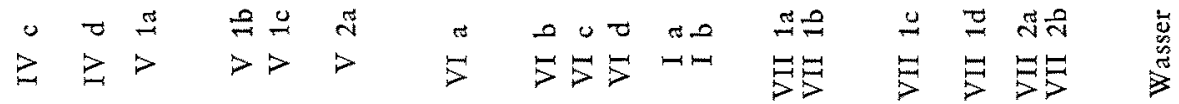

\begin{tabular}{|c|c|c|c|c|}
\hline$\hat{\imath}^{2}$ & $\stackrel{\sim}{*}$ & 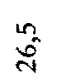 & $\ddot{x}$ & \\
\hline 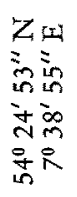 & 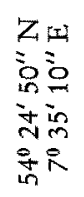 & 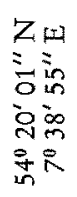 & 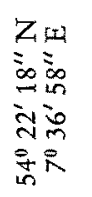 & \\
\hline ڤ & $\stackrel{2}{2}$ & $\stackrel{1}{\circ}$ & $\stackrel{\text { }}{\stackrel{\sigma}{\sigma}}$ & $\stackrel{\circ}{\circ}$ \\
\hline$\sigma^{\circ}$ & $\sigma^{\circ}$ & $\sigma$ & $\sigma$ & $\sigma$ \\
\hline$\infty$ & $\infty$ & $\infty$ & 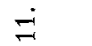 & $\stackrel{\mathfrak{I}}{ }$ \\
\hline
\end{tabular}




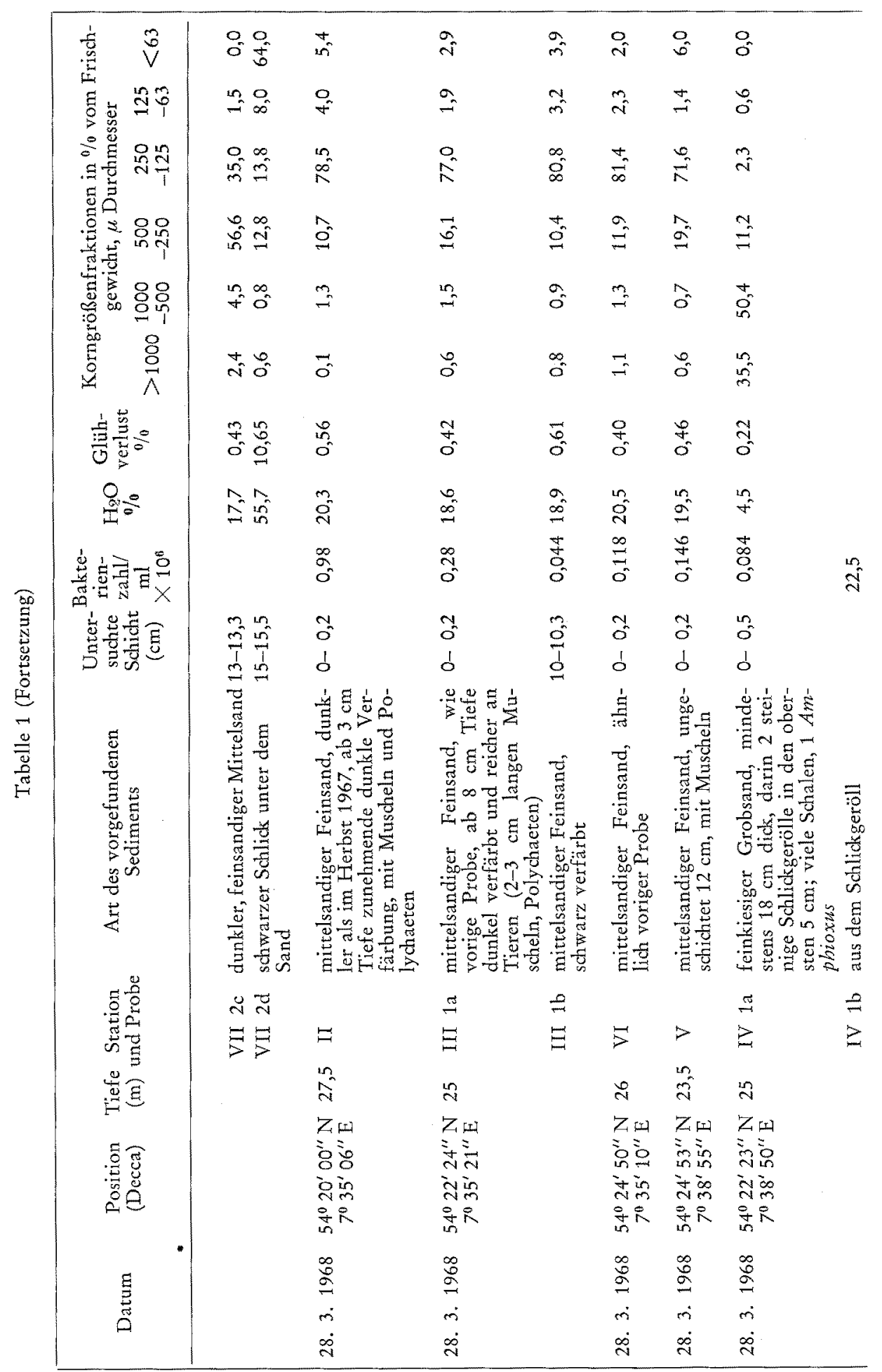




\begin{tabular}{|c|c|c|c|c|c|c|c|}
\hline$\overline{2}$ & & & $\stackrel{0}{\sim}$ & & & $\stackrel{2}{a}$ & \\
\hline $\bar{r}$ & & & $\stackrel{0}{=}$ & & & $\hat{\infty}^{-}$ & \\
\hline $\begin{array}{l}\infty \\
10\end{array}$ & & & $\frac{N}{\infty}$ & & & 是 & \\
\hline 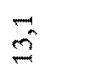 & & & $\overrightarrow{0}$ & & & in & \\
\hline$\stackrel{+}{=}$ & & & \pm & & & $\stackrel{0}{\rightarrow}$ & \\
\hline 2 & & & $\hat{0}$ & & & $\stackrel{0}{0}$ & \\
\hline $\begin{array}{l}\infty \\
+ \\
0\end{array}$ & & $\stackrel{\circ}{0}$ & & $\begin{array}{ll}F_{0} & F \\
0\end{array}$ & & $\cong$ & \\
\hline : & & $\overrightarrow{8}$ & & $\stackrel{i}{=}$ & & $\begin{array}{l}\text { in } \\
\text { in }\end{array}$ & \\
\hline है & $\stackrel{m}{\rightarrow}$ & $\ddot{0}$ & 营 & $\begin{array}{ll} \pm & \infty \\
\\
0\end{array}$ & & in & \\
\hline $\begin{array}{l}0 \\
0 \\
0\end{array}$ & & $\begin{array}{l}\text { z } \\
0 \\
d\end{array}$ & $\overrightarrow{7} \stackrel{3}{1}$ & 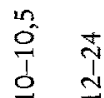 & & $\begin{array}{l}y \\
0 \\
1 \\
0\end{array}$ & \\
\hline 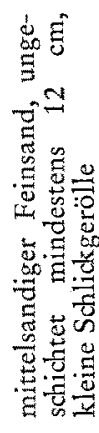 & 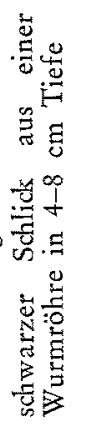 & 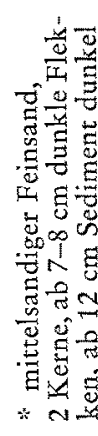 & 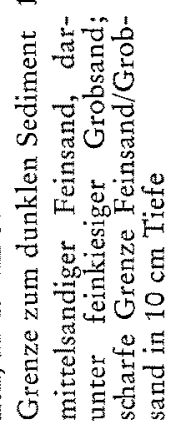 & 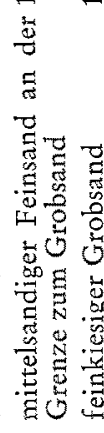 & 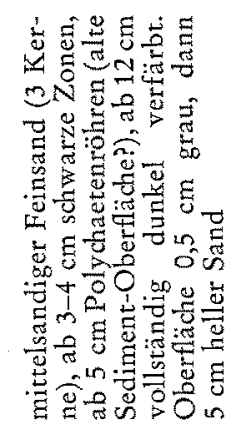 & 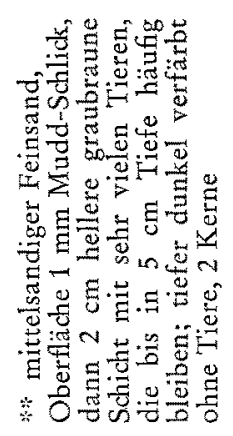 & \\
\hline (I) & مـ & तూ & ती त्य & $\vec{ि}$ & & & \multirow{7}{*}{ 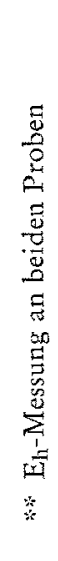 } \\
\hline$\mapsto$ & - & $\Xi$ & $\Xi 2$ & $\geq Z$ & 5 & & \\
\hline $\begin{array}{l}n^{2} \\
0^{2}\end{array}$ & & $\stackrel{9}{4}$ & $\stackrel{2}{2}$ & & $\ddot{n}$ & $\vec{y}$ & \\
\hline 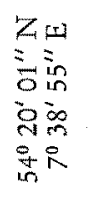 & & 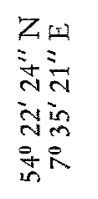 & 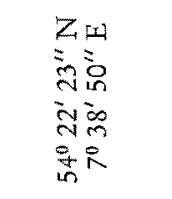 & & 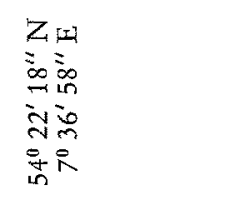 & 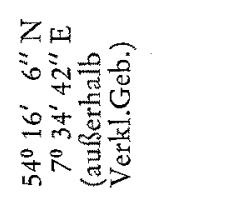 & \\
\hline$\stackrel{\infty}{\mathscr{\Xi}}$ & & $\stackrel{\infty}{\circ}$ & $\stackrel{2}{2}$ & & $\stackrel{\circ}{2}$ & $\stackrel{\circ}{\circ}$ & \\
\hline$\dot{m}$ & & $\dot{m}$ & $\dot{r}$ & & $\dot{r}$ & $\dot{m}$ & \\
\hline$\stackrel{\infty}{\sim}$ & & i & $\dot{2}$ & & $\dot{\pi}$ & $\stackrel{i}{ }$ & \\
\hline
\end{tabular}


REINECK entnommen (REINECK 1963). Im September kam auf "Gauss" (außer auf Station II) der große Kastengreifer (Kastengröße $20 \times 30 \times 45 \mathrm{~cm}$ ), im März das kleine Modell (Kastengröße $10 \times 17 \times 25 \mathrm{~cm}$ ) zum Einsatz. In beiden Untersuchungszeiträumen herrschte ruhiges Wetter. Probennahme und Methoden der Aufarbeitung

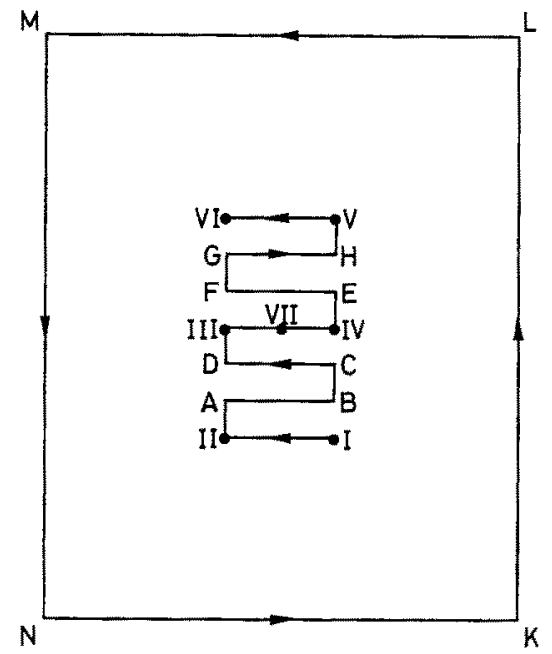

Abb. 3: Der mir konstanter Geschwindigkeir gefahrene Kurs bei der Aufnahme des Echogramms. Kurs K L M N K liegt $4 \mathrm{sm}$ vom Rand des Verklappungsgebiets entfernt

der Proben waren die gleichen wie die bei Hrckel \& Gunkel (1968) beschriebenen. Untersucht wurde in erster Linie die Sedimentoberfläche, doch wurden auch zahlreiche Proben aus tieferen Schichten des Sedimentkerns analysiert.

Die Korngrößenverteilung wurde durch Naßsieben, der Gehalt an organischer Substanz als Glühverlust bei $550^{\circ} \mathrm{C}$ bestimmt. Der Wassergehalt wurde durch 18 stündiges Trocknen ermittelt und das Redoxpotential frisch an Deck geholter Sedimentkerne mit einem BECKMANN-pH-Meter und Platinelektrode gemessen. Die Keimzahl der eiweißzersetzenden, heterotrophen Bakterien wurde mit der Gußplattenmethode erhalten. Die Keimzahlbestimmungen wurden im September 1967 an Bord der „Gauss", im März 1968 nach kurzem Transport im Institut auf Helgoland durchgeführt. In Tabelle 1 sind die Meßwerte zusammen mit der Beschreibung der Sedimentschichtung zusammengestellt.

\section{ERGEBNISSE}

Zunächst wird an Hand von Parallelproben aus der Sedimentoberfläche die natürliche Heterogenität des Wassergehalts, der organischen Substanz und vor allem der Bakterienzahl untersucht, wie sie innerhalb einer Kastengreiferprobe $\left(600 \mathrm{~cm}^{2}\right)$, auf einer Station (Decca-Position) und im ganzen 2,5 × 5 Seemeilen großen Untersuchungsgebiet vorkommt (Tab. 2). Damit wird ein Anhaltspunkt gewonnen, welche Flächenstücke sich noch signifikant unterscheiden. Die Parallelproben a und b der Keim- 
zahlbestimmungen an denselben Sedimentkernen bestanden aus je $1 / 3$ der Oberflächen in verschiedenen Hälften des Kernes; nur bei Station VII 1 wurden weitgehend identische Proben von der ganzen Oberfläche genommen, die dann auch weit besser übereinstimmen (Tab. 2). Man erkennt, daß die Unterschiede in der Bakterienhäufigkeit an der Sedimentoberfläche innerhalb einer Kastengreiferprobe manchmal schon so groß

Tabelle 2

Heterogenität von Wassergehalt, Glühverlust und Bakterienkeimzahl an der Sedimentoberfläche des zukünftigen Verklappungsgebiets. 1 und 2 sind verschiedene Sedimentkerne auf gleicher Station; $a$ und b Parallelproben am selben Kern

\begin{tabular}{|c|c|c|c|c|}
\hline Station & Probe & $\underset{\%}{\mathrm{H}_{2} \mathrm{O}}$ & $\begin{array}{c}\text { Glühverlust } \\
\% \%\end{array}$ & $\begin{array}{l}\text { Bakterienzahl } \\
\times 10^{6} \text { pro } \mathrm{ml}\end{array}$ \\
\hline \multicolumn{5}{|c|}{ September 1967} \\
\hline I & $a, b$ & 20,1 & 0,77 & $\begin{array}{l}13,4 \\
11,2\end{array}$ \\
\hline II & $\begin{array}{ll}1 & \mathrm{a} \\
2 & \mathrm{a}\end{array}$ & $\begin{array}{l}18,0 \\
13,4\end{array}$ & $\begin{array}{l}0,30 \\
0,21\end{array}$ & $\begin{array}{l}4,0 \\
2,5\end{array}$ \\
\hline III & $a, b$ & 17,8 & 0,44 & $\begin{array}{r}8,0 \\
10,0\end{array}$ \\
\hline IV & $a, b$ & 17,3 & 0,55 & $\begin{array}{l}2,4 \\
3,2\end{array}$ \\
\hline V & $\begin{array}{ll}1 & \mathrm{a} \\
2 & \mathrm{a}\end{array}$ & $\begin{array}{l}17,6 \\
20,5\end{array}$ & $\begin{array}{l}0,56 \\
0,68\end{array}$ & $\begin{array}{l}4,4 \\
6,8\end{array}$ \\
\hline VI & $a, b$ & 19,1 & 0,74 & $\begin{array}{l}8,4 \\
9,2\end{array}$ \\
\hline VII & $1 a, b$ & 19,3 & 0,67 & $\begin{array}{l}10,0 \\
10,8\end{array}$ \\
\hline & $2 a, b$ & 18,4 & 0,74 & $\begin{array}{r}9,4 \\
13,6\end{array}$ \\
\hline \multicolumn{5}{|c|}{ März 1968} \\
\hline I & a & 20,6 & 0,46 & 0,32 \\
\hline II & & 20,3 & 0,56 & 0,98 \\
\hline III & $1 \mathrm{a}$ & 18,6 & 0,42 & 0,28 \\
\hline & $2 a$ & 20,1 & 0,60 & 0,60 \\
\hline IV & $1 \mathrm{a}$ & 4,5 & 0,22 & 0,084 \\
\hline V & & 19,5 & 0,46 & 0,146 \\
\hline VI & & 20,5 & 0,40 & 0,118 \\
\hline
\end{tabular}

sein können wie die $z$ wischen kilometerweit entfernten Stationen. Für 5 Wertpaare von Parallelproben der Keimzahlbestimming an denselben Sedimentkernen im September 1967 wird eine mittlere Abweichung der Einzelwerte vom Mittelwert von $11 \%$ gefunden. Bei Parallelproben auf gleicher Station sind es $16 \%$ Abweichung (3 Wertepaare).

Die Bakterienzahlen in den Oberflächenproben aller genommenen Kerne im September schwanken $z$ wischen 2,5 und $12,3 \times 10^{6}$ pro $\mathrm{ml}$ entsprechend einem Verhältnis von 1 : 5. Die Abweichung der Werte vom Mittelwert beträgt im Durchschnitt $43 \%$, die der entsprechenden Oberflächenwerte im Frühjahr 1968 im Durchschnitt $68 \%$. Stoßrohrproben, die nur ca. 7 bis $13 \mathrm{~cm}^{2}$ Sedimentoberfläche liefern, können bei der Untersuchung der Bakterien der Sedimentoberfläche nur recht unzureichende, weil zu 
stark streuende Werte liefern. Ein von allen Teilen der Oberfläche eines großen Kastengreiferkernes genommene Probe wird der Sache eher gerecht.

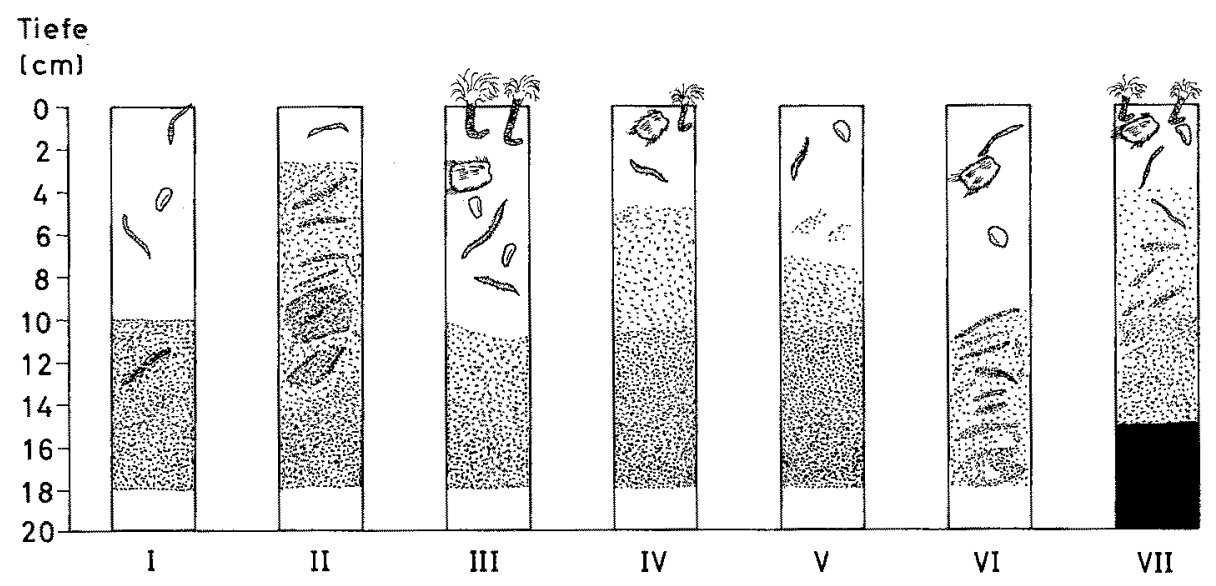

Abb. 4: Schichtung und Tierbesiedlung im Sediment des zukünftigen Verklappungsgebiets im September 1967 auf den Stationen I bis VII. Die Dichte der Punktierung entspricht der Dunkel-

färbung des Sediments. Isolierte Schlickblätter durch dichte Punktierung hervorgehoben

Im Frühjahr 1967 wurde im Gebiet nördlich, nordwestlich und westlich Helgolands eine deutliche Uberschichtung des Sediments mit einer hellen Sandschicht gefunden, was auf die Wirkung der Orkane im Winter 1966/67 zurückgeführt werden dürte (Hickel \& Gunkel 1968). Einige Proben in der genannten Arbeit wurden in der Nähe des zukünftigen Verklappungsgebiets, eine darin genommen, so daß hier ein Anschluß an jene Werte möglich ist.

Betrachtet man die Schichtungsverhältnisse des Sediments im September 1967, erkennt man eine helle, aerobe Schicht auf dunkelgefärbtem Sand (Abb. 4). Es ist dies die „neue" Sandschicht vom vergangenen Winter, die aber gegenüber den Befunden im Frühjahr (Hickel \& Gunkel 1968) wieder reichlich mit Makrofauna besiedelt und etwas dunkler gefärbt war. Muscheln, Herzigel und Polychaeten waren häufig; die Größe der Muscheln überstieg aber $2 \mathrm{~cm}$ nicht.

Die Korngrößenbestimmungen ergaben, daß die oberste Sandschicht aus mittelsandigem Feinsand, das dunkle Sediment darunter aus feinsandigem Mittelsand bestand (Tab. 1). 60 bis $80 \%$ des Sandes hatten einen Korndurchmesser von 500 bis $250 \mu$ bzw. 250 bis $125 \mu$. Der Sand war also gut sortiert, was auf kräftige Wasserbewegung schließen läßt. Auf Station I und besonders Station VII wurde eine sehr scharfe Trennung $z$ wischen hellem und dunkelgefärbtem Sediment beobachtet. Auf Station VII war dies Schlick in $15 \mathrm{~cm}$ Tỉefe. Möglicherweise lag auch bei anderen Stationen Schlick im Untergrund, wurde aber in den meist nur 18 bis $20 \mathrm{~cm}$ langen Sedimentkernen nicht erfaßt.

Die Mittelwerte besonders der Bakterienanzahlen für Schichten unterschiedlicher Tiefenlage bis in ca. $15 \mathrm{~cm}$ sind deutlich verschieden (Tab. 3). Abgesehen von der verständlicherweise bakterienreichsten Sedimentoberfläche zeigen sich nahe der Grenzzone 
Tabelle 3

Mittlere Vertikalverteilung der Meßswerte im Sediment des zukünftigen Verklappungsgebiets im Herbst 1967

\begin{tabular}{|c|c|c|c|c|}
\hline Tiefe und Sedimentart & $\underset{0 \%}{\mathrm{H}_{2} \mathrm{O}}$ & $\begin{array}{l}\text { Glïhverlust } \\
\% \%\end{array}$ & $\begin{array}{l}\text { Bakterienzahl } \\
\times 10^{6} \text { pro ml }\end{array}$ & $\begin{array}{l}\text { Anzahl der } \\
\text { gemittelten } \\
\text { Werte (nur } \\
\text { Bakterien) }\end{array}$ \\
\hline $\begin{array}{l}\text { Obertläche }(0-0,2 \mathrm{~cm}) \text { Sand } \\
\text { mit Sinkstoffen }\end{array}$ & 18,2 & 0,58 & 7,96 & 16 \\
\hline $\begin{array}{l}5 \mathrm{~cm} . \text { Homogener Sand mit } \\
\text { Tieren }\end{array}$ & 17,2 & 0,49 & 2,8 & 6 \\
\hline $\begin{array}{l}10 \mathrm{~cm} . \text { Sand nahe der } \\
\text { Grenzzone }\end{array}$ & 18,9 & 0,68 & 7,13 & 3 \\
\hline $\begin{array}{l}\text { Altes Sediment darunter, } \\
\text { schwarz }\end{array}$ & 17,9 & 0,60 & 0,055 & 2 \\
\hline
\end{tabular}

zwischen hellem und dunklem Sediment, der mutmaßlichen alten Sedimentoberfläche, stark erhöhte Bakterienanzahlen. An dieser Grenzfläche wurden im Frühjahr viele abgestorbene sedentäre Polychaeten gefunden (HrCKeL \& Gunkei 1968). Wenig unterhalb davon nimmt die Zahl der aeroben Bakterien rasch ab und liegt zwei Zehnerpotenzen niedriger als an der Oberfläche, trotz erhöhtem Gehalt an organischer Substanz.

Für die Beziehung von Bakterienanzahl zu organischer Substanz an der Sedimentoberfläche im September 1967 findet man eine gute Korrelation (Korrelationskoeffizient $\mathrm{x}=0,74)$. Eine ähnlich gute Korrelation dieser Werte, jedoch mit ganz anderer Steigung der Regressionsgeraden, wird nach den bei Hickel \& Gunkel (1968) angegebenen Werten vom 25. April 1967 in der Sedimentoberfläche des benachbarten Gebiets gefunden (Abb. 5).

$\mathrm{Da}$ im Winter 1966/67 eine Sandumschichtung beobachtet worden war, interessiert nun die Veränderung im Winter 1967/68. Abbildung 6 zeigt die Korngrößenverteilung und Bakterienanzahlen auf gleichen Stationen jeweils im Herbst 1967 und im Frühjahr 1968. Die Korngrößenverteilung auf den Stationen I, III, V und VII hat sich kaum geändert. Wesentlich anders ist das Sediment dagegen auf Station IV, wo im Frühjahr feinkiesiger Grobsand in einer eigenartigen Lagerung angetroffen wurde. Ein Kern (18 cm tief) bestand aus feinkiesigem Grobsand, in den Schlickgerölle eingelagert waren; in einem zweiten Kern auf gleicher Station wurde die Grobsandschicht unter $10 \mathrm{~cm}$ mittelsandigem Feinsand gefunden. Es scheint also ein - vielleicht nur sehr kleines - Bodenstück zu geben, wo unter dem mittelsandigen Feinsand eine Grobsandschicht liegt, die die Oberfläche erreichen kann. Man kann allerdings nicht sagen, ob diese Lagerung erst im Winter 1967/68 entstanden ist. Da sie von nur kleiner Ausdehnung sein kann, ist es möglich, daß sie im Herbst 1967 vom Kastengreifer nicht getroffen wurde. Vergleicht man diese Schichtung mit dem Befund auf Station VII im Herbst 1967, wo Schlick in $15 \mathrm{~cm}$ Tiefe angetroffen wurde (Tab. 1, Abb. 4), so erkennt man in diesem scheinbar so gleichförmigen Bodenstïck eine erstaunliche Vielfalt von Sedimentationsbedingungen. 
Im Winter 1967/68 kann kein Anzeichen für eine neuerliche Umschichtung des Sandes an der Oberfläche gefunden werden. Die Oberflächensandschicht ist nur noch dunkler geworden, die Grenze zum schwarzgefärbten, tieferliegenden Sediment ist aber noch zu erkennen. Im Gegensatz zu den bei Hickel \& Gunkel (1968) besprochenen Verhältnissen im Vorjahr kann daher nun der Einfluß der Jahreszeit auf die Bakterien-population in der Sedimentoberfläche beurteilt werden. In der nunmehr ungestörten Sedimentoberfläche kann man in den im Herbst gegenüber dem Frühjahr 10- bis 100fach höheren Bakterienkeimzahlen (Abb. 6) die Auswirkung der Sedimentation des vom Plankton stammenden Detritus und der im Herbst 12 bis $15^{\circ} \mathrm{C}$ höheren Wassertemperatur sehen.

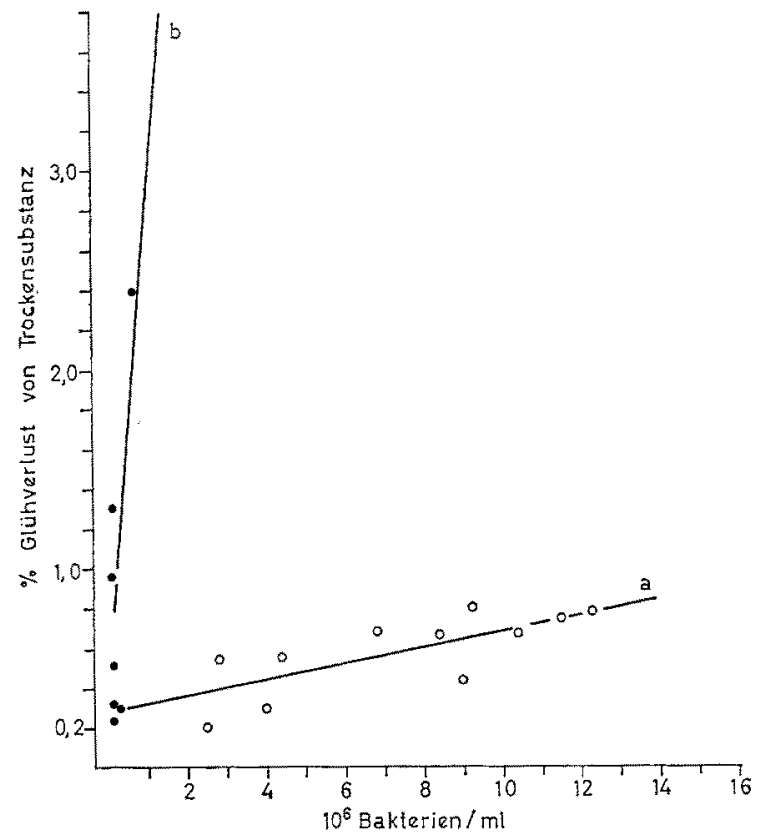

Abb. 5: Beziehung zwischen organischer Substanz (als Glühverlust) und Bakterienzahl an der Sedimentoberfläche nordwestlich Helgolands. $a=$ Regressionsgerade der Werte (Kreise) aus dem zukünftigen Verklappungsgebiet im September 1967, $\mathrm{b}=$ Regressionsgerade der Werte aus dem benachbarten Gebiet im April 1967

Die Redoxpotentialmessungen im März 1968 zeigten (Station III), daß der Sand bis in 5 bis $6 \mathrm{~cm}$ Tiefe einen gleichhohen Oxydationsgrad aufwies. Erst in $7 \mathrm{~cm}$ begann ein Abfall des $E_{h}-$ Wertes $(+370 \mathrm{mv}$ in $1 \mathrm{~cm}$ bis $+275 \mathrm{mv}$ in $7 \mathrm{~cm}$ Tiefe). Vergleichsweise dazu wurden am gleichen Tag Redoxpotentialmessungen in zwei Kernen der unweit gelegenen tieferen Mulde $(41 \mathrm{~m})$ zwischen Feuerschiff „P 8 “ und Helgoland durchgeführt: Von $+230 \mathrm{mV}$ in $1 \mathrm{~cm}$ Sedimentriefe fiel der $E_{\mathrm{h}}$-Wert rasch auf $+30 \mathrm{mV}$ in $8 \mathrm{~cm}$, in der Parallelprobe sogar von $+100 \mathrm{mV}$ in $1 \mathrm{~cm}$ auf $+10 \mathrm{mV}$ in $8 \mathrm{~cm}$. Der höhere Anteil an organischer Substanz und die hier fehlende Umschichtung im Vorjahr (Hickel \& Gunkel 1968) lassen in diesen Mulden keine so gute Durchlüftung zu wie im Sediment des zukünftigen Verklappungsgebietes. 


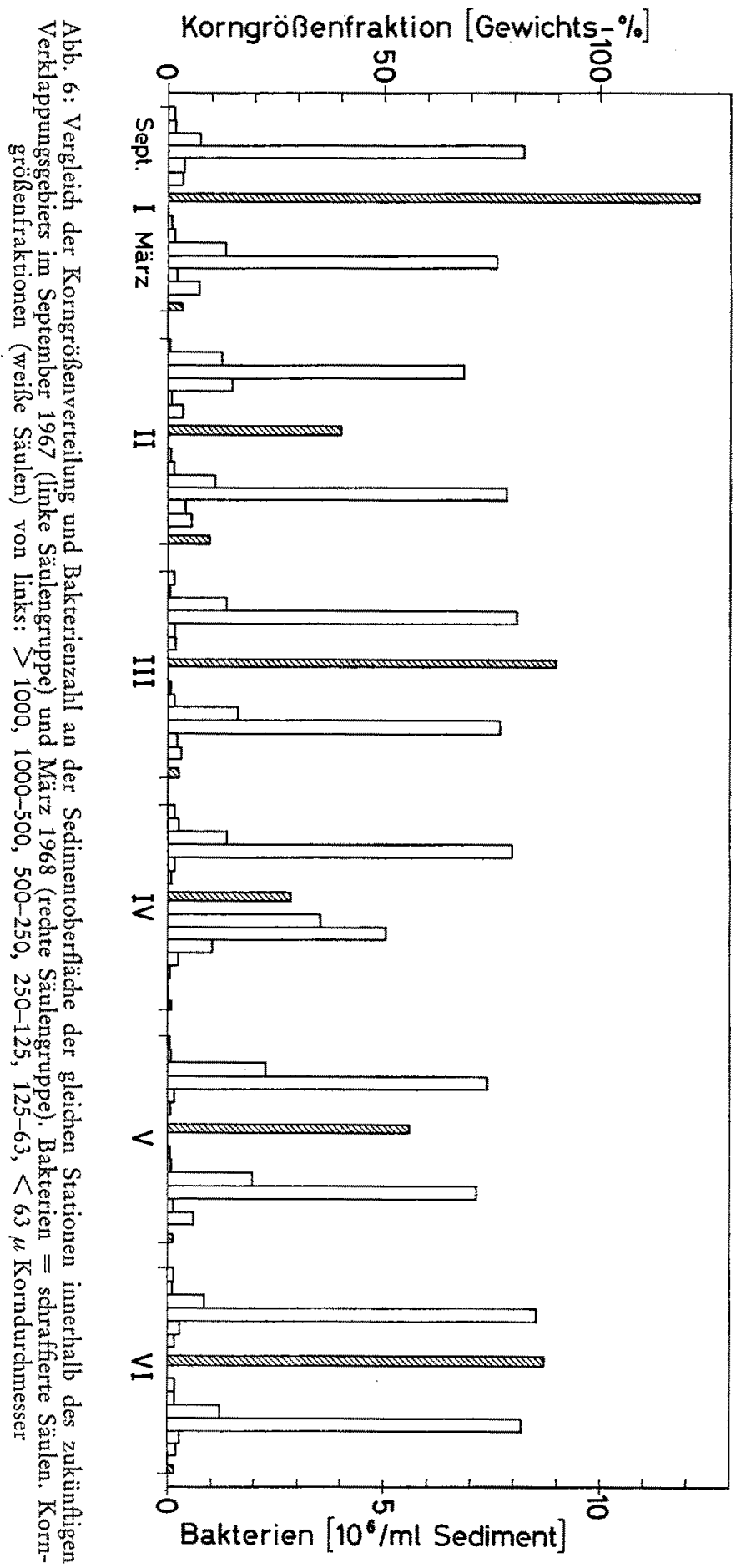




\section{DISKUSSION}

Da die Art der Sedimentbedeckung ein Ausdruck der hydrographischen Verhältnisse, besonders der Strömungen in Bodennähe ist, darf man nach den Befunden auf Station VII und IV mit örtlich begrenzten, ganz von den normalen Verhältnissen abweichenden Bodenströmen im zukünftigen Verklappungsgebiet rechnen, was bei dem relativ ebenen Boden erstaunlich ist. Im Hinblick auf den weiteren Verbleib der zu erwartenden Eisenhydroxid-Ausflockungen beim Einbringen der Abwässer ${ }^{1}$ wird man vielleicht noch intensivere Bodenstromuntersuchungen anstreben müssen, als die vom Deutschen Hydrographischen Institut bisher durchgeführten. Es sind auch die Auswirkungen der zyklonalen Reststromwirbel im Untersuchungsgebiet auf die Vermischung und den Verbleib der Abfallstoffe zu diskutieren.

Wie sich zeigte, war unser Stationsnetz nicht ausreichend, um die Ausdehnung der Grobsandlagen bei Station IV zu beurteilen. Auch wären längere Sedimentkerne als $20 \mathrm{~cm}$ wünschenswert gewesen, um auch auf anderen Stationen mögliche Schlicklagen unter dem Sand zu finden. Die Schlick-Sand-Grenze könnte man dann als Bezugsfläche zur Erkennung weiterer Aufschüttung oder Abtragung des Sandes benutzen.

Im Hinblick auf unsere Sedimentuntersuchungen interessiert die mögliche biologische Veränderung des Benthos durch das Einbringen der Abwässer. Dabei scheint weniger deren Giftigkeit (Kinne \& Schumann 1968), sondern eher die Sedimentation des Eisenhydroxids von Bedeutung zu sein.

Um die Bildung und Sedimentation von Eisenhydroxidflocken im Meerwasser zu beobachten, wurde im Laborversuch stark verdünnte $\mathrm{FeSO}_{4}$-Lösung in natürliches Nordseewasser von Helgoland eingebracht, das in einem "Planktonkreisel“, wie er bei Greve (1968) beschrieben wird, bewegt und durchlüftet wurde. Die in diesem für Planktonzüchtung konstruierten Behälter erzeugte langsame Rotationsbewegung stellt eine gute Annäherung an die natürlichen Turbulenzverhältnisse im Meer dar, wie sie auf das Seston im Meerwasser einwirken.

Es bildete sich zunächst nach wenigen Minuten ein sehr feiner Eisenhydroxidniederschlag, der nicht erkennbar sedimentierte. Dieser Niederschlag wurde aber rasch gröber; die feinen Flocken klebten zusammen und bildeten nach einem Tag bereits etwa 0,5 bis $3 \mathrm{~mm}$ große Partikel, die dann rasch sedimentierten. Die Hydroxidflocken setzten sich trotz der Wasserbewegung bald auf dem Boden ab, das Wasser wurde wieder klar, nur noch vereinzelte, sehr lockere Partikel blieben in der Schwebe. Die zum Vergleich in unbewegtem Wasser gebildeten Hydroxidflocken blieben sehr viel kleiner.

Nach einem Monat wurden aus der geschlossenen, ca. $1 \mathrm{~mm}$ dicken Schicht des auf dern Sandboden des Planktonkreisels sedimentierten Eisenhydroxids Proben mikroskopiert. Die Oberfläche dieser Schicht bestand aus lockeren, lose zusammenhängenden Flocken von etwa $0,25 \mathrm{~mm}$ Größe. Viel kompakter waren die Hydroxidflocken an der Untergrenze der Schicht, wo sie in rundlichen Partikeln von etwa 0,25 bis 0,35 , maximal $0,5 \mathrm{~mm}$ Durchmesser aneinanderhingen. Beim Versuch der Zerteilung mit einer

1 Die zur Verklappung vorgesehenen Abwässer sind ein Gemisch aus Dünnsäure (mit ca, $18 \% \mathrm{H}_{2} \mathrm{SO}_{4}$ und $13 \% \mathrm{FeSO}_{4}$ ) und Grünsalz (mit $50 \% \mathrm{FeSO}_{4}$ ). Die genaue Zusammensetzung ist bei KINNE \& SchumanN (1968) zu ersehen. 
Nadel erwiesen sie sich als recht zäh und klebten alsbald wieder zusammen. In der Hydroxidschicht wurden einige Ciliaten und Nematoden beobachtet.

Die Oberfläche des Sandbodens im Planktonkreisel war nach einem Monat durch die geschlossene Hydroxidschicht wesentlich verfestigt, so daß nur kräftigste Wasserbewegungen diese Schicht zerstörten. Sand wurde dagegen viel leichter aufgewirbelt. Man muß allerdings berücksichtigen, daß bei der verwendeten Versuchsanordnung eine langsame Filterung des Wassers durch den Sand hindurch erfolgt, was die Wirkung der Verfestigung des Sandes durch die Sinkstoffe erhöht.

Man wird damit rechnen müssen, daß nach dem Verklappen der eisenhaltigen Abwässer sich bald Eisenhydroxid am Boden des Verklappungsgebiets, aber auch in größerem Umkreis davon, absetzen wird. Dies wird besonders in den Mulden der Fall sein, wie man sich durch Tauchbeobachtungen an Sinkstoffen leicht überzeugen kann. Die im Echogramm (Abb. $2 \mathrm{a}$ und $\mathrm{b}$ ) angezeigten flachen Mulden von maximal $4 \mathrm{~m}$ Tiefe und etwa 2 bis $4 \mathrm{sm}$ Größe könnten dabei schon zu einer lokalen Anreicherung an Sinkstoffen beitragen. Je länger die Hydroxidflocken suspendiert sind, desto größer werden die Bodenstrecken sein, über die sie von der Gezeitenströmung verteilt werden. Die Dauer der Suspension im Wasser hängt einerseits von der im Versuch beobachteten Vergrößerung der Flocken im bewegten Seewasser $a b$, andererseits von der Wasserturbulenz durch den Tidenstrom und besonders der Windeinwirkung.

Hierbei erscheint die Tatsache bedeutend, daß bereits $4 \mathrm{sm}$ westlich des Verklappungsgebiets eine $40 \mathrm{~m}$ tiefe Mulde mit einem relativ steilen Abhang beginnt. Da allein die Wasserversetzung durch die Tide (etwa $9 \mathrm{sm}$ in West-Ost-Richtung) die Wasserkörper vom Verklappungsgebiet über diese Mulde bringt, muß man hier mit einer Anreicherung von Sinkstoffen am Boden rechnen, und zwar einmal, weil tieferes Wasser weniger turbulent ist, die Sedimentation also rascher erfolgt, zum anderen, weil sedimentiertes Material vom $40 \mathrm{~m}$ tiefen Boden nur sehr viel schwerer wieder aufgewirbelt und resuspendiert werden kann als vom $25 \mathrm{~m}$ tiefen Boden des Verklappungsgebiets. Dies geht ja bereits aus den Sedimentalanalysen aus der 40-m-Mulde hervor (Tab. 1, letzte Probe, und Hickel \& Gunkel 1968). Stets wurde in dieser Mulde eine Anreicherung feiner, an organischer Substanz reicher Sinkstoffe gefunden.

Conwin \& Keтchum (1956) fanden, daß nach jahrelanger Verklappung eisenhaltiger Abwässer in der New York Bight eine Anreicherung des Eisens am Boden nur in Verbindung mit einer Anreicherung feinster natïrlicher Sinkstoffe (Silt und Mudd) angetroffen werden konnte. Dies ist auch zu erwarten, da die Eisenhydroxidflocken durch die gleichen physikalischen Vorgänge wie das natürliche Seston am Boden angereichert werden. In einigen wissenschaftichen Untersuchungen, die für die amerikanische Industrie ausgeführt wurden, wird das Fehlen einer signifikanten Anderung des Eisengehalts im Sediment und der Benthospopulationen nach teilweise jahrelanger Verklappung eisensulfat- und schwefelsäurehaltiger Abwässer in der New York Bight berichtet (ARnold \& Royce 1950, Owen 1956, Redfield \& Walford 1951). Es handelt sich allerdings nur um stichprobenhafte Untersuchungen, deren Unvollständigkeit und Unzulänglichkeit auch betont werden. Es scheint nur an der gleichen Stelle untersucht worden zu sein, wo die Verklappung stattfand, was nur sinnvoll wäre, wenn man nach genauer Kenntnis der Hydrographie des Gebiets den Verbleib der Wasserkörper am selben Ort beweisen kann, zumal die Wassertiefe in der New York Bight etwa doppelt 
so groß und damit die Sedimentationszeit viel länger ist als im vorgesehenen Verklappungsgebiet bei Helgoland.

Eine Verfestigung der Sandoberfläche im. Untersuchungsgebiet bei Helgoland, wie sie nach unseren Beobachtungen diskutabel erscheint, muß für die Benthosorganismen von Bedeutung sein einmal durch die Verminderung mechanischer Veränderung der Sandoberfläche (Sandtrift), zum anderen durch die Beeinflussung chemischer und physikochemischer Prozesse. Dabei wird dem Gasaustausch zwischen Wasser und Sediment besondere Aufmerksamkeit gewidmet werden müssen; bei stärkerer Bedeckung des Bodens durch eine Hydroxidschicht muß man befürchten, daß das Sediment unter dieser Schicht anaerob wird.

Auch bei geringen Mengen des Hydroxids am Boden ist zu bedenken, daß Filtrier-, Respirations- und Fortbewegungsorgane bodenlebender Organismen beeinträchtigt werden können. So wurde beobachtet, daß solche Niederschläge Eupagurus im Aquarium behinderten und Mollusken-Veliger sich darin verfingen (KInNe \& SchumanN 1968). Man müßte ferner untersuchen, wie die zahlreichen Filtrierer des Benthos mit den großen Flocken des gealterten Hydroxids fertig werden. Die Bemerkung von Keтснuм et al. (1958), daß frisch ausgeflocktes Eisenhydroxid innerhalb der Filtrierkapazität der meisten Zooplankter liegt und von Cladoceren im Laborversuch ohne Schaden aufgenommen wurde, dürfte wohl kaum auch für die gealterten Hydroxidflocken zutreffen.

Wenn die Organismen mit der Konsistenz der Hydroxidflocken fertig werden können und diese als Nahrung aufnehmen, ist die Eigenschaft von Eisenhydroxid, adsorbierend zu wirken, wichtig. Keтchum et al. (1958) erwähnen, daß unter dem Mikroskop ein flaumiger Belag auf dem Hydroxid zu erkennen ist, der aus feinteiliger organischer Substanz bestehen und für die Filtrierer als Nahrung von Bedeutung sein dürfte. Man kann sich unschwer vorstellen, daß diese adsorptive Wirkung eine wesentliche Anreicherung gelöster und feinpartikulärer organischer Substanz an der Bodenoberfläche bewirken und dann einen förderlichen Effekt auf die Quantität der Benthosorganismen haben könnte, vorausgesetzt, daß sie das Hydroxid fressen können und nicht durch sekundäre Effekte, wie einem Sauerstoffschwund im Sediment, geschädigt werden. Allerdings muß auch die Möglichkeit der Adsorption und Anreicherung von giftigen Ionen, wie sie in den genannten Abwässern vorhanden sind, an das Hydroxid bedacht werden.

Sollten Makrofauna und Bakterien im Sediment von wesentlicher Bedeutung für die Verarbeitung des Eisenhydroxids am Boden sein, so wird man deren ganz unterschiedlicher Aktivität im Sommer und Winter Rechnung tragen müssen. Die Abfallstoffe würden sich das ganze Jahr über am Boden ansammeln, aber nur während einiger Sommermonate biologisch verändert werden.

\section{ZUSAMMENFASSUNG}

1. In einem zukünttigen Verklappungsgebiet schwefelsäure- und eisensulfathaltiger Industrieabwässer einer Titandioxidfabrik, das $11,5 \mathrm{sm}$ nordwestlich Helgolands gelegen und $2,5 \times 5 \mathrm{sm}$ groß ist, wurden Untersuchungen der Sedimenteigenschaf- 
ten und des Bakteriengehalts im Sediment durchgeführt. Auf 7 Stationen wurden an Kastengreifer-Sedimentkernen im September 1967 und März 1968 Korngrößenverteilung, Glühverlust, Wassergehalt, Redoxpotential und Keimzahl heterotropher Bakterien bestimmt (Tab. 1).

2. Bei Parallelbestimmungen der Bakterienkeimzahl in $600 \mathrm{~cm}^{2}$ großen Flächenstücken im September fand sich eine mittlere Abweichung der Einzelbestimmungen vom Mittelwert mit $11 \%$, bei Parallelproben auf gleicher Station mit $16 \%$. Die natürliche Heterogenität besonders der Bakterienzahl ist so groß, daß erst Mittelwerte aus der Oberfläche großer Kastengreiferproben als repräsentativ angesprochen werden können.

3. Bakterienzahlen von 2,5 bis $12,3 \times 10^{6}$ im September 1967 und 0,08 bis $0,98 \times 10^{6}$ im März 1968 wurden in den obersten Millimetern des Sediments im ganzen Untersuchungsgebiet gefunden mit einer mittleren Abweichung vom Mittelwert von $43 \%$ im Herbst und $68 \%$ im Frühjahr. Der Glühverlust blieb stets unter $1 \%(0,2$ bis $0,8 \%$. Das Sediment bestand aus gut sortiertem mittelsandigem Feinsand oder feinsandigem Mittelsand. Isolierte, wahrscheinlich engbegrenzte Vorkommen von feinkiesigem Grobsand an der Oberfläche deuten auf die Wirkung von Bodenströmen, die ganz von den normalen Verhältnissen abweichen, hin. Veränderliche Sedimentationsbedingungen zeigt auch ein Schlickvorkommen in $15 \mathrm{~cm}$ Sedimenttiefe an.

4. Eine neuerliche Uberschichtung des Sediments mit aufgewirbeltem Sand, wie sie im vorhergehenden Winter beobachtet wurde, ließ sich im Winter 1967/68 nicht feststellen. Die im Frühjahr 1967 erkennbare neue Sandschicht war im Herbst 1967 wieder reichlich mit Makrofauna besiedelt. Der Boden war bis in mindestens $7 \mathrm{~cm}$ Tiefe gut durchlüftet. Die alte Sedimentoberfläche war in etwa $10 \mathrm{~cm}$ Tiefe noch meist gut an der Dunkelfärbung zu erkennen und durch erhöhten Bakteriengehalt ausgezeichnet.

5. Auf gleichen Oberflächenstücken des Sediments wurden im Herbst (September) gegenüber dem Frühjahr (März) 10- bis 100fach höhere Bakterienzahlen gefunden bei ähnlicher Menge organischer Substanz. Bei teilweise guter Korrelation von Bakterienzahl mit organischer Substanz wurde im Frühjahr eine sehr geringe Zunahme der Bakterienzahl, im Herbst eine rasche Zunahme mit steigendem Gehalt des Sediments an organischer Substanz gefunden (Abb. 4).

6. Beim Einbringen der Industrieabwässer in das Untersuchungsgebiet ab 1969 interessiert für die mögliche Veränderung des Benthos weniger die Giftwirkung der Abwässer als vor allem die Sedimentation des gebildeten Eisenhydroxids. Ein dazu angestellter Versuch über Bildung und Sedimentation des Hydroxids im bewegten, durchlüfteten Wasser eines "Planktonkreisels“, eines Planktonzuchtgefäßes, gab Hinweise auf Größe und Sedimentierverhalten der Hydroxidflocken und die Verfestigung einer lockeren Sandoberfläche nach einem Monat durch die gealterte Hydroxidschicht, deren Auswirkung bedeutend sein könnte für Mikro-, Meio- und Makrobenthos, was aber noch der Untersuchung bedarf. Nach Beginn der Verklappung wird man besonders die Bodenmulden nicht nur im Verklappungsgebiet selbst, sondern auch im weiteren Umkreis davon auf Anreicherung von Eisenhydroxid untersuchen müssen. 
Danksagung. Herrn Dr. W. Gunkel sei an dieser Stelle für die Unterstützung der mikrobiologischen Arbeiten, Herrn K. Treutner für seine gewissenhafte Mitarbeit gedankt.

\section{ZITIERTE LITERATUR}

Arnold, E. L. \& Royce, W. F., 1950. Observations of the effect of acid-iron waste disposal at sea on animal populations. Spec. scient. Rep. U.S. Fish Wildl. Serv. (Fish.) 11.

Corwin, N. \& Ketchum, B. H., 1956. The iron content of sediment samples in New York Bight obtained during $\mathrm{R} / \mathrm{V}$ Caryn cruise 108. Oceanographic Institution, Woods Fole, Mass., Ref. No 57-19 (unpubl. Ms.).

GoEDECKE, E., 1939. Ober unperiodische Wasserversetzungen in der Deutschen Bucht. Rapp. P.-v. Réun. Cons. perm. int. Explor. Mer 109 (3), 89-92.

- 1941. Beiträge zur Hydrographie der Konvergenz der Deutschen Budht. Annln Hydrogr. Berl. 69 (11), 345-362.

- 1968. Uber die hydrographische Struktur der Deutschen Bucht im Hinblick auf die Verschmutzung in der Konvergenzgrenze. Helgoländer wiss. Meeresunters. 17, 108-125.

Greve, W., 1968. The "planktonkreisel", a new device for culturing zooplankton. Mar. Biol. $1(3), 201-203$.

HrCKEL, W. \& Gunkel, W., 1968. Untersuchungen über die Häufigkeit der Bakterien in der obersten Sedimentschicht der Deutschen Bucht in Beziehung zu den Substrateigenschaften. Helgoländer wiss. Meeresunters. 18, 213-231.

KALLE, K., 1956. Chemisch-hydrographische Untersuchungen in der inneren Deutschen Bucht. Dt. bydrogr. Z. 9, (2), 55-65.

Ketchum, B. H., YenTsCh, C. S. \& Corwin, N., 1958. Some studies of the disposal of iron wastes at sea. $\mathrm{I}$. The distribution of plankton in relation to the circulation and chemistry of the water. Oceanographic Institution, Woods Hole, Mass., Ref. No 58-55 (unpubl. Ms.).

Kinne, O. \& Schumann, K. H., 1968. Biologische Konsequenzen schwefelsäure- und eisensulfathaltiger Industrieabwässer. Mortalität junger Gobius pictus und Solea solea (Pisces). Helgoländer wiss. Meeresunters. 17, 141-155.

Neumann, H. \& Meier, C., 1964. Die Oberflächenströme in der Deutschen Bucht. Dt. hydrogr. Z. 17, 1-40.

OwEN, D. M., 1956. Report on the bottom sampling and self-contained diving survey in the New York Bight. Oceanographic Institution, Woods Hole, Mass., Ref. No 57-5 (unpubl. Ms.).

ReDfietd, A. C. \& WALford, L. A., 1951. A study of the disposal of chemical waste at sea. Publs natn. Res. Coun., Wash. 201, 1-49.

ReinecK, H. E., 1963. Der Kastengreifer. Die Entwicklung eines Gerätes zur Entnahme ungestörter, orientierter Grundproben vom Meeresboden. Natur Mus., Frankf. 93, 102-108.

Anschrift des Autors: Dr. W. HickEL

Biologische Anstalt Helgoland

Meeresstation

2192 Helgoland 